\title{
МЕТОДИЧЕСКИЕ ПРОБЛЕМЫ ТЕРМОЛЮМИНЕСЦЕНТНОГО ДАТИРОВАНИЯ ГОЛОЦЕНОВЫХ ЭОЛОВЫХ И МОРСКИХ ОТЛОЖЕНИИ
}

В последние годы в геологической практике с разной степенью успешности достаточно широко применяется термолюминесцентное (ТЛ) датирование (Шелкопляс, 1971; Хютт, Смирнов, 1977; Hütt и др., 1979, 1982; Hütt, Smirnov, 1983; Власов, Куликов, 1979; Wintle, Huntley, 1980; Wintle и др., 1984; Prószynska, 1983; Mejdahl, 1985; Jungner, 1985; Bluszcz, Pasdur, 1985).

В поле зрения исследователей находится целый ряд разногенетических образований: эоловые, морские, аллювиальные, флювиогляциальные и другие. Центральной проблемой в настоящее время является поиск методически достоверной датировки и повышение точности метода (Wintle, Huntley, 1982; Singhvi, 1982; Mejdahl, 1985).

Проблемы датирования сводятся к реконструкции остаточной председиментационной возрастной информации, связанной с геологическим прошлым минералов, находящихся в составе пород к моменту седиментации. Как известно, возрастная информация минералов формируется с учетом воздействия радиоактивных элементов, входящих в состав как самих минералов, так и окружающей их породы $\left({ }^{238} \mathrm{U},{ }^{232} \mathrm{Th},{ }^{40} \mathrm{~K}\right)$. В процессе транспорта (в зависимости от генетического типа отложений различными способами) к месту седиментации под воздействием механической дезинтеграции, факторов выветривания и солнечного света происходит существенное стирание запасенной минералами информации и цикл нового накопления начинается с момента седиментации под влиянием радиационного фона в месте формирования отложения (рис. 1).

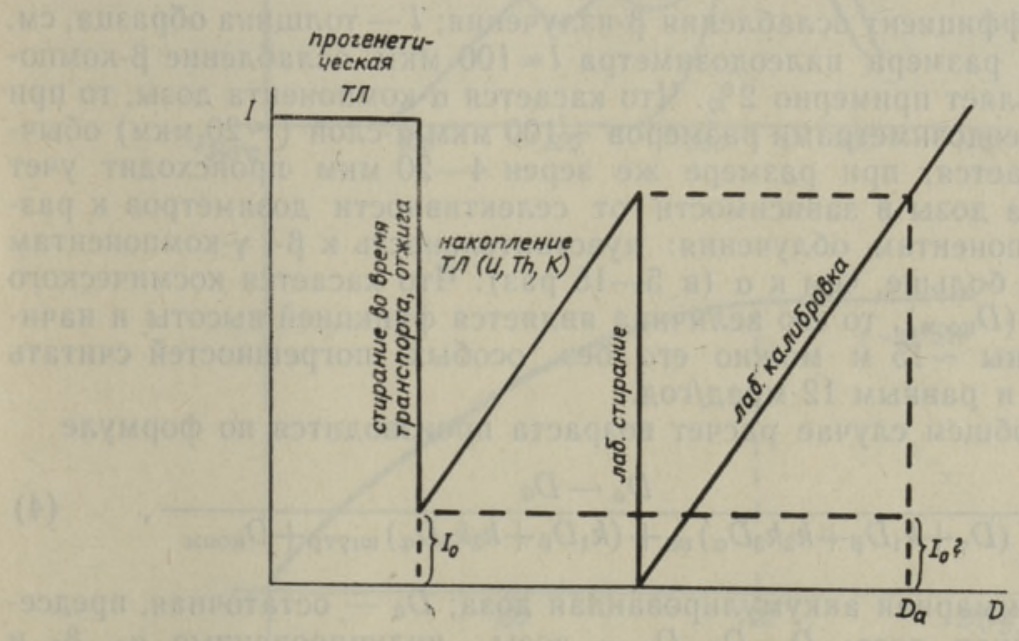

Рис, 1. Схема формирования и детектирования возрастной информации, запасенной минералами из отложений, $I_{0}$ - остаточная прогенетическая ТЛ. 
Возрастная информация в лабораторных условиях достигается обесцвечиванием или нагревом минералов с последующей калибровкой, детектируемая при этом термолюминесценция (светосумма) пропорциональна времени природного облучения и величине природного радиационного фона. Момент седиментации (возраст отложения) определяется по формуле

$$
T_{\text {лет }}=\frac{D_{a}}{D_{\mathrm{r}}},
$$

где $D_{a}$ - аккумулированная за время существования отложения минералом-палеодозиметром доза; $D_{\mathrm{r}}$ - годичная доза или скорость накопления аккумулированной дозы, определяемая содержанием радиоактивных компонентов.

В общем случае величина $D_{a}$ определяется согласно экспоненциальному закону, что следует из экспериментов и хорошо согласуется с теоретической моделью:

$$
I_{E}=I_{\infty}\left(1-l^{-a D a}\right),
$$

где $I_{E}-$ интенсивность ТЛ, соответствующая $D_{a} ; I_{\infty}-$ интенсивность ТЛ, соответствующая дозе насыщения; $a$ - константа, определяющая чувствительность дозиметра к облучению. Однако $D_{a}$ в большинстве случаев содержит некоторую неопределенную остаточную $D_{0}$, связанную с неполной стираемостью прогенетической светосуммы к моменту седиментации (рис. 1).

Годичная доза формируется за счет вклада $\alpha-, \beta-, \gamma$-компонентов радиоактивного распада природных изотопов, входящих в окружающую минерал породу (внешняя доза), либо в сам минерал (внутренняя доза), а также за счет влияния космического компонента облучения. В связи с тем, что проникающая способность различных компонентов радиоактивного распада для породы различна ( $\alpha$-облучение $\sim 20$ мкм; $\beta \sim 2$ мм; $\gamma \sim 30 \mathrm{~cm})$, при расчете $D_{\mathrm{r}}$ вводятся специальные поправочные коэффициенты, связанные с размерами минеральных зерен - палеодозиметров. Величина ослабления $\beta$-компонента дозы $G_{\beta}$ в зависимости от размера палеодозиметра производится по формуле (Jokoyama и др., 1982).

$$
G_{\beta}=\left(1-l^{-\mu} \beta^{l}\right) / \mu_{\beta} l,
$$

где $\mu_{\beta}$ - коэффициент ослабления $\beta$-излучения; $l$ - толщина образца, см.

Так, для размера палеодозиметра $l=100$ мкм ослабление $\beta$-компонента составляет примерно $2 \%$. Что касается $\alpha$-компонента дозы, то при работе с палеодозиметрами размеров $\sim 100$ мкм $\alpha$-слой $(\sim 20$ мкм) обычно стравливается; при размере же зерен 4-20 мкм происходит учет $\alpha$-компонента дозы в зависимости от селективности дозиметров к различным компонентам облучения: чувствительность к $\beta$-, $\gamma$-компонентам существенно больше, чем к $\alpha$ (в 5-15 раз). Что касается космического компонента $\left(D_{\text {косм}}\right)$, то его величина является функцией высоты и начиная с глубины $\sim 15$ м можно его без особых погрешностей считать постоянным и равным 12 мрад/год.

Итак, в общем случае расчет возраста производится по формуле

$$
T=\frac{D_{a}-D_{0}}{\left(D_{\gamma}+k_{1} D_{\beta}+k_{2} k_{3} D_{\alpha}\right)_{\text {вн }}+\left(k_{1} D_{\beta}+k_{2} k_{3} D_{\alpha}\right)_{\text {внутр }}+D_{\text {косм }}},
$$

где $D_{a}-$ суммарная аккумулированная доза; $D_{0}$ - остаточная, председиментационная доза; $D_{\alpha}, D_{\beta}, D_{\nu}-$ дозы, индуцированные $\alpha-, \beta-$ и $\gamma$-излучателями природных радиоизотопов; $k_{1}, k_{2}-$ коэффициенты ослабления $\alpha$ - и $\beta$-излучения, обусловленные размерами детектора; $k_{3}-$ коэф- 
фициент селективности к $\alpha$-излучению; $D_{\text {косм }}-$ космический компонент облучения.

В настоящее время в качестве палеодозиметров большинство исследователей используют кварц, полевые шпаты, циркон, кальцит, полиминеральные фракции. При этом в различных методиках размеры зерен, сепарируемых различными методами минералов, варьируют от 4 до 300 мкм. Выбор конкретного минерала и конкретной методики в существенной степени диктуется генезисом отложений и ориентировочным возрастом датируемых событий.

В настоящей работе объектом исследования были пески из дюн и морских отложений. Выбранные типы отложений представляли большой методический интерес в связи с длительной световой экспозицией, реализуемой в процессе формирования отложений, что является необходимым условием для стирания предэкспозиционной информации минералов, ибо именно свет является основным стирающим фактором. В качестве палеодозиметров были выбраны К-полевые шпаты и кварц (100-300 мкм). Методы получения мономинеральных фракций показаны на рис. $2, a$ и $3, a$. Следует отметить, что использование для минеральной сепарации тяжелой жидкости вольфрамата натрия («Sometu»,

a)
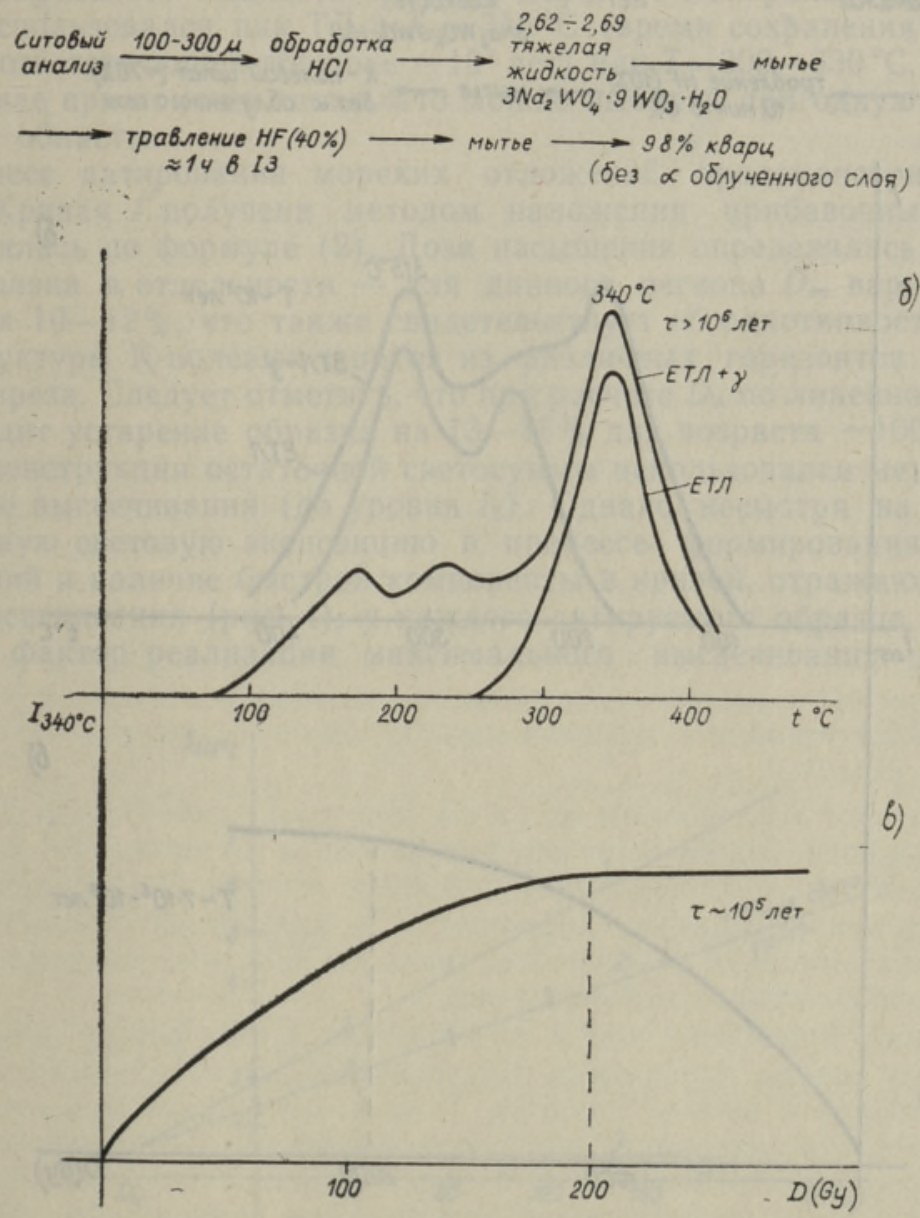

Рис. 2. Способ получения мономинеральных фракций $(a)$; люминесцентные (б) и дозиметрические (в) свойства кварца осадочных отложений. 
ФРГ) вместо бромоформа существенно упрощает процедуру сепарации, а главное, делает ее безвредной для оператора, так как реактив не обладает токсичными свойствами.

В методических целях были выбраны хорошо исследованные геологами регионы - морские отложения разреза Затон (Архангельская обл.) и некоторые дюнные отложения из северной части Эстонии.

На рис. 4 показаны кривые, отражающие процесс стирания прогенетической светосуммы под воздействием видимой части солнечного спектра у К-полевых шпатов и кварцев. Быстрая компонента, составляющая $70 \%$ от общей светосуммы в полевом шпате, стирается за 10-15 мин и минимально достижимый уровень составляет всего $\sim 1 \%$ от уровня насыщения. Для кварца эти параметры существенно хуже, что и определило выбор К-полевых шпатов в качестве палеодозиметров при датировании данного типа отложений. Кроме того, возрастной диапазон исследуемых морских отложений был достаточно широк (нижний предел 100 тыс. лет), что также исключало возможность удачи при использовании кварца в качестве палеодозиметра в связи с более ранним насыщением по дозе (рис. 2, в и 3,8 ).

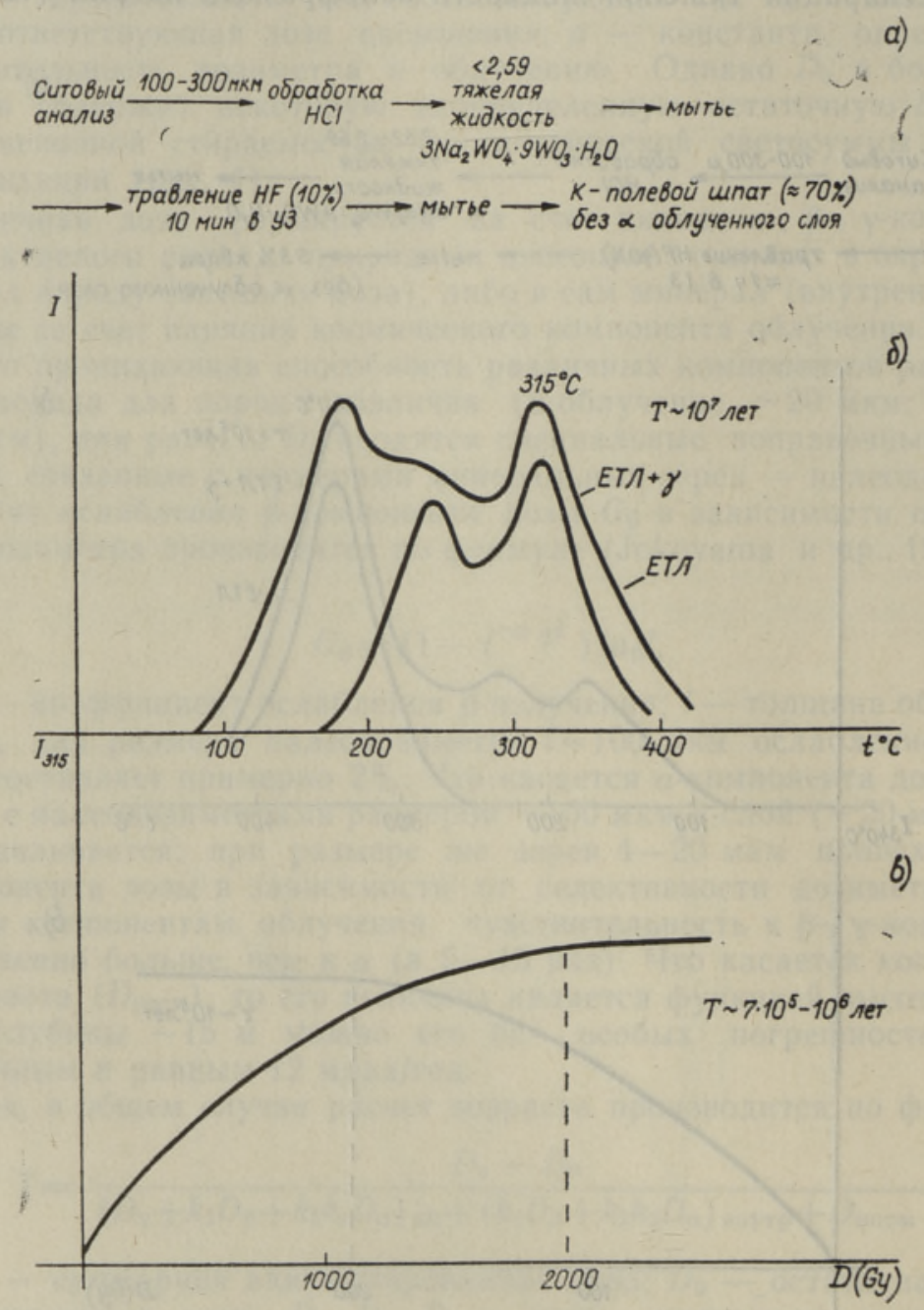

Рис. 3. Способ получения мономинеральных фракций $(a)$; люминесцентные (б) и дози, метрические $(в)$ свойства К-полевых шпатов из осадочных отложений, 


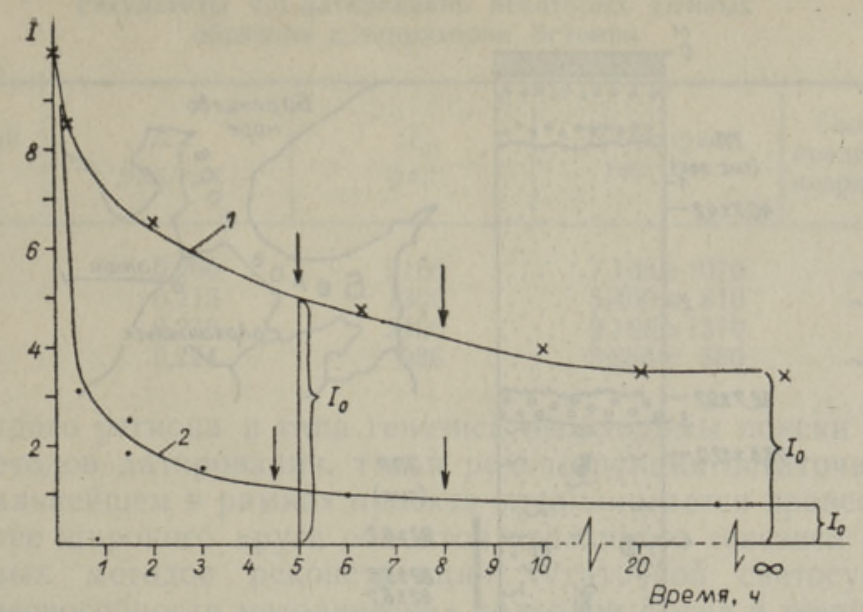

Рис. 4. Процесс стирания запасенной светосуммы кварца (1) и К-полевых шпатов (2).

На рис. 2,б показана кривая ТЛ К-полевых шпатов, типичная для Северо-Западного региона (очевидно, место сноса - Скандинавский щит - определяет общность природы дефектов минерала). Для датирования использовался пик ТЛ с $T_{\mathrm{M}}=315^{\circ} \mathrm{C}$ (время сохранения информации в соответствующей ловушке $\sim 10^{7}$ лет) или $T=300-330^{\circ} \mathrm{C}$. В последнем случае при помощи тест-плато можно выбрать пригодную для датирования область.

Процесс датирования морских отложений продемонстрирован на рис. 5. Кривая 1 получена методом наложения прибавочных доз, $D_{a}$ определялась по формуле (2). Доза насыщения определялась для каждого образца в отдельности - для данного региона $D_{\infty}$ варьировала в пределах 10-12\%, что также свидетельствует об однотипности дефектной структуры K-полевых шпатов из различных горизонтов исследуемого разреза. Следует отметить, что при расчете $D_{a}$ по линейному закону происходит устарение образца на $13-15 \%$ для возраста 100 тыс. лет. Для реконструкции остаточной светосуммы использовался метод максимального высвечивания (до уровня $I_{0}$ ). Однако несмотря на довольно длительную световую экспозицию в процессе формирования морских отложений и наличие быстрой компоненты в кривой, отражающей динамику высвечивания (рис. 4), у каждого датируемого образца контролировался фактор реализации максимального высвечивания. Для этого

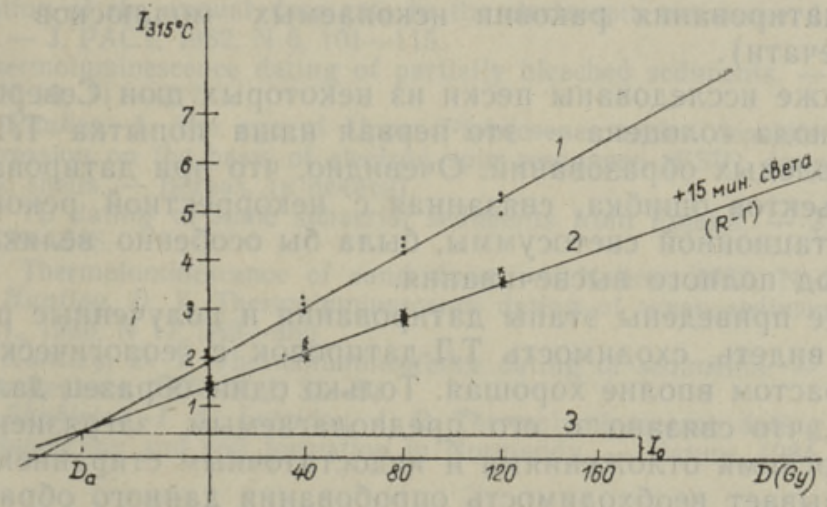

Рис. 5. Процесс датирования одного из образцов морских отложений из разреза Затон (Архангельская область). 1 - метод прибавочных доз; $2-\mathrm{R}$-Г-метод. 


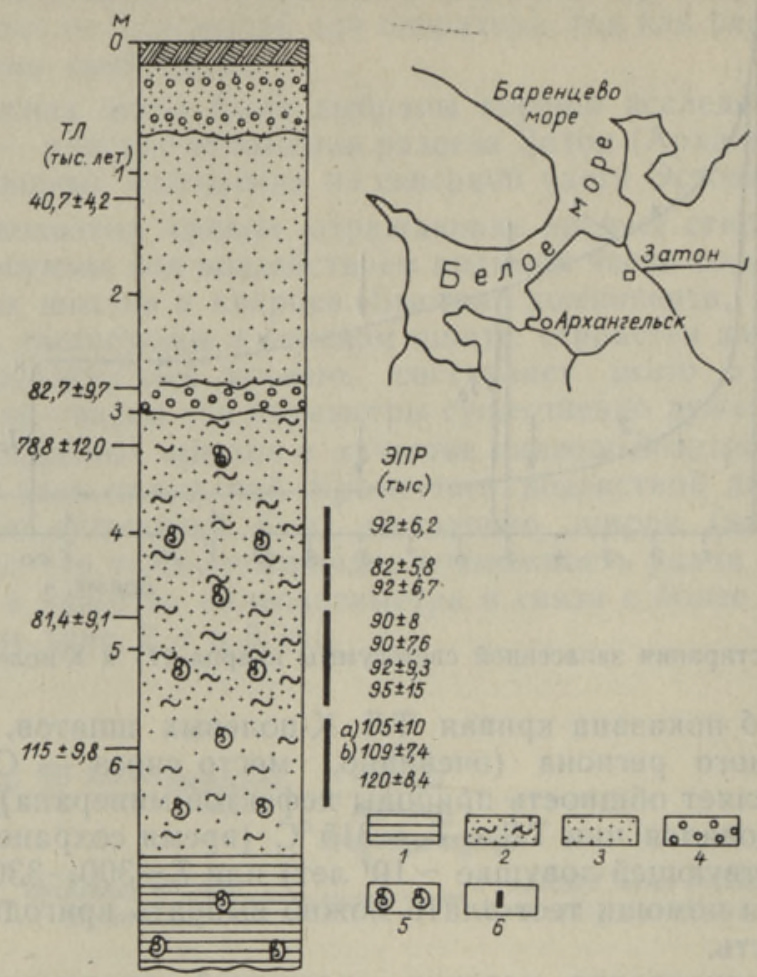

Рис. 6. Местоположение и строение исследованного разреза. 1 - глины; 2 - песок алевритовый; 3 - песок; 4 - гравий и галька; 5 - раковины моллюсков; 6 - место отбора образцов.

использовался R-Г-метод (Wintle, Huntley, 1982), где в случае реализации максимального высвечивания все три графика имеют общую точку пересечения, определяющую реальную $D_{a}^{\prime}=D_{a}-D_{0}$.

Следует отметить, что в большинстве случаев для образцов из приведенного разреза ситуация максимального высвечивания реализовывалась, только для одного из образцов к моменту седиментации сохранилась бо́льшая, чем $D_{0}$ остаточная светосумма.

На рис. 6 приводится один из разрезов и ТЛ-датировка отдельных горизонтов. Полученные даты согласуются с геологическими моделями процессов в этом регионе (Девятова и др., 1981), а также с результатами ЭПР-датирования раковин ископаемых моллюсков (Molodkov, Raukas, в печати).

Были также исследованы пески из некоторых дюн Северо-Западной Эстонии периода голоцена - это первая наша попытка ТЛ-датирования столь молодых образований. Очевидно, что при датировании таких молодых объектов ошибка, связанная с некорректной реконструкцией председиментационной светосуммы, была бы особенно велика. Использовался метод полного высвечивания.

В таблице приведены этапы датирования и полученные результаты. Қак можно видеть, сходимость ТЛ-датировок с геологически предсказуемым возрастом вполне хорошая. Только один образец дал завышенный возраст, что связано с его предполагаемым загрязнением более старыми морскими отложениями и недостаточным стиранием светосуммы. Это вызывает необходимость опробования данного образца дополнительно R-Г-методом. Однако следует отметить, что для крупных зерен (100-300 мкм) R-Г-метод не всегда пригоден. 


\begin{tabular}{c|c|c|c|c}
\hline $\begin{array}{c}\text { Лабораторный } \\
\text { нндекс }\end{array}$ & $\begin{array}{c}Д_{2}, \\
\text { рад/год }\end{array}$ & $\begin{array}{c}д_{a}, \\
\text { рад }\end{array}$ & $\begin{array}{c}\text { ТЛ-возраст, } \\
\text { тыс. лет }\end{array}$ & $\begin{array}{c}\text { Геологически } \\
\text { предполагаемый } \\
\text { возраст, тыс. лет }\end{array}$ \\
\hline 424 & 0,266 & 2166 & $7,160 \pm 1070$ & $\sim 7-8$ \\
425 & 0,213 & 1300 & $5,400 \pm 810$ & $\sim 76-7$ \\
428 & 0,230 & 2400 & $9,180 \pm 1370$ & $7,800\left({ }^{14} \mathrm{C}\right)$ \\
429 & 0,224 & 986 & $3,880 \pm 580$ & $\sim 4$
\end{tabular}

Для каждого региона и типа генезиса необходимы поиски как оптимальных методов датирования, так и реконструкция остаточной светосуммы. В дальнейшем в рамках проекта предполагается провести исследования более широкого круга объектов указаннфго генезиса с привлечением новых методов реконструкции остаточной светосуммы для проверки дееспособности методических подходов. Тогда в тесном сотрудничестве с геологами станет возможным проведение геологической интерпретации полученных результатов с целью палеогеографической и палеоклиматической реконструкции событий в исследуемых регионах.

\section{ЛИТЕ Р А Т У Р А}

Власов В. К., Куликов О. А. К методике термолюминесцентного датирования геологических объектов. - Изв. АН СССР. Сер. геол., 1979, № 11, 90-97.

Девятова Э. И., Раукас А. В., Раямяэ Р. А., Хютт Г. И. Верхнеплейстоценовый разрез Пасьва (р. Вага, Архангельская область) и его стратиграфическое значение. Бюл. комис. по изуч. четвертич. периода, 1981, № 51, 38-50.

Хютт Г. И., Смирнов А. В. Дозиметрические свойства природного кварца и перспектива использования его для термолюминесцентного датирования геологических объектов. - Изв. АН СССР. Сер. физ., 1977, 41, № 7, 1367-1369.

Шелкопляс B. H. Датирование четвертичных отложений термолюминесцентным методом. - В кн.: Хронология ледникового века. М., 1971, 307.

Bluszcz, A., Pasdur, M. F. The comparison of the TL and ${ }^{14} \mathrm{C}$-dates for young eolian sediments - a check of the zeroing assumption validity. - Nucl. Tracks, 1985, N $10,703-711$.

Hütt, G., Smirnov, A., Tale, $Y$. On the application of thermoluminescence of natural quartz to the study of sedimentary deposits. - J. PACT, 1979, N 3, 362-373.

Hütt, G., Smirnov, A., Punning, J.-M. Problems in measuring annual dose. - J. PACT, $1982, \mathrm{~N} \mathrm{6}, 27-33$.

Hütt, G., Smirnov, A. Thermoluminescence dating of sediments by means of the quartz and feldspar inclusion method. - J. PACT, 1983, N 9, 463-471.

Jungner, $H$. Some experiences from an attempt to date postglacial dunes from Finland. Nucl. Tracks, 1985 , N 10, 749-757.

Jokoyama, Y., Nguyen, H., Quagebeur, Y., Poupeau, G. Some problems encountered in the evaluation of the annual dose rate in the electrospin resonance dating of fossil bones. - J. PACT, 1982, N 6, 101-115.

Mejdahl, $V$. Thermoluminescence dating of partially bleached sediments. - Nucl. Tracks, 1985 , N 10, $711-717$.

Molodkov, A., Raukas, A. The age of Upper Pleistocene marine deposits of the boreal transgression on the basis of electron spin resonance (ESR) dating of subfossil mollusc shells. - Boreas, (в печати).

Prószynska, $H$. TL dating of some subaerial sediments from Poland. - J. PACT, 1983, N $9,539-546$.

Singhvi, $A$. K. Thermoluminescence of sand dunes. - Nature, 1982, N 299, 376-380.

Wintle, A. G., Huntley, D. Y. Thermoluminescence dating of ocean sediments. - Can. J. Earth Sci., 1980, N 17, 348-360.

Wintle, A. G., Huntley, D. Y. Thermoluminescence dating of sediments. - J. Quaternary Science Reviews, 1982, N 1, 31-51.

Wintle, A. G., Shakleton, J. J., Latzidou, J. P. Thermoluminescence dating of periods of loess deposition and soil formation in Normandy. - Nature, 1984, N 310, 491-
493 . 


\section{HOLOTSEENSETE EOOLILISTE JA MERESETETE DATEERIMINE TERMOLUMINESTSENTSMEETODIL}

Uurimused näitavad, et kaaliumpäevakivid on kõige perspektiivsemad mineraalid eooliliste ja meresetete vanuse määramiseks termoluminestsentsmeetodil. Artiklis on esitatud Eesti holotseensete eooliliste setete ja Arhangelski oblasti keskpleistotseeni meresetete vanuse määrangud, mis on saadud eelgeneetilise valgussumma rekonstrueerimisega. Tulemused on kooskōlas teiste meetoditega saadud dateeringutega ning üldgeoloogilise hinnanguga.

\section{Galina HOTT}

\section{THERMOLUMINESCENCE DATING OF HOLOCENE EOLIAN AND MARINE SEDIMENTS}

Methodological problems of thermoluminescence dating of eolian and marine sediments are described. On the basis of performed studies it is shown that K-feldspars are perspective paleodosimeters for TL-dating of sediments of the above-mentioned genesis. TL-dating results of the Holocene eolian sediments from Estonia and the Middle Pleistocene marine sediments from Arkhangelsk district with reconstructed residual lightsum are presented. The results are in good agreement with those obtained by other dating methods and geological models. 